\section{The ulnar digital artery perforator flap}

Sir,

This letter is with regards to our article on the ulnar digital artery perforator flap that was published in IJPS recently. ${ }^{[1]}$ Following the publication, another article about a similar flap was bought to our notice. This article by Uchida et al. ${ }^{[2]}$ from Tokyo Medical University, Japan, essentially described the same flap with anatomical studies. We missed this publication in our initial literature search.

We apologise for claiming priority in describing the flap and would like to acknowledge Uchida et al. as having described the flap first.

Uchida et al. performed cadaveric dissections in 10 hands and observed that there were on an average from three to seven branches of the ulnar palmar digital artery and had at least one branch between the MCP joint and $10 \mathrm{~mm}$ proximal to the MCP joint. We performed cadaveric dissections and dye studies in four limbs and found that three to four perforators were seen to arise at regular intervals from the underlying digital artery to form a continuous longitudinal vascular arcade in the flap overlying the hypothenar eminence. The larger caliber perforators on visual inspection were those near the MCP joint, distal to the distal palmar crease.

Uchida et al. have used this flap primarily for Dupuytrens contracture with a subcutaneous pedicle of $8 \mathrm{~mm} \times 8 \mathrm{~mm}$ including the distal perforators of the ulnar palmar digital artery. They have covered defect in the distal palmar region and achieved primary closure of the donor site. We have used this flap only for burn contractures. However, we have islanded the flap on the distal perforator of the ulnar palmar digital artery, and our flap has successfully resurfaced defects beyond the distal interphalyngeal joint. We were able to close the donor defects primarily. Uchida et al. think that this flap is a good option for skin defect of the distal palm and proximal fingers. We feel that if islanded and isolated on the perforator, this flap is a good option resurfacing the entire flexor aspect of the little finger.

Also, as per the Gent perforator flap nomenclature consensus, ${ }^{[3]}$ the name of this flap should be "Small finger palmar ulnar digital artery perforator flap".

\section{Nikhil Panse, Parag Sahasrabudhe}

Department of Plastic Surgery, B.J. Medical College and Sasoon Hospital, Pune, India.

Address for correspondence: Dr. Nikhil Panse, Vimal Niwas, Sudarshan Society, Near Model colony post office, Shivajinagar, Pune 16, India. E-mail: nikhil.panse@rediffmail.com

\section{REFERENCES}

1. Panse N, Sahasrabudhe P. The ulnar digital artery perforator flap: A new flap for little finger reconstruction: A preliminary report. Indian J Plast Surg 2010;43:190-4.

2. Uchida R, Matsumara H, Imai R, Tanaka K, Watanabe K. Anatomical study of the perforators from the ulnar palmar digital artery of the little finger and clinical uses of digital artery perforatorflaps. Scand J Plast Reconstr Surg Hand Surg 2009;43:90-3.

3. Blondeel PN, Van Landuyt KH, Monstrey SJ, Hamdi M, Matton GE, Allen RJ, et al. The "Gent" consensus on perforator flap terminology: Preliminary definitions. Plast Reconstr Surg 2003;112:1378-83; quiz 1383, 1516; discussion 1384-7.

\begin{tabular}{|l|l|}
\hline \multicolumn{3}{|c|}{ Access this article online } \\
\hline Quick Response Code: & Website: \\
\hline & www.jps.org \\
\cline { 2 - 3 } & DOI: \\
\hline
\end{tabular}

